\title{
SEQUENCE AND DATE OF ERUPTION OF PERMANENT TEETH IN A GROUP OF CHILDREN IN EL-GHARBIA GOVERNORATE
}

\author{
Lamis Ahmed Elghareb*, Amina Elhosary* and Amal Ezat**
}

\begin{abstract}
Introduction: Teeth eruption is a dynamic, genetically process which is a part of the odontogenesis and comprises all the tooth movement from the bone crypt until reaching the occlusal plane and starting its function.

Objectives: The present study was carried out to determine the eruption dates of permanent teeth, also to study bilateral and maxillo-mandibular differences in the eruption of teeth and finally to assess sequence of permanent teeth eruption among a group of children in El Gharbia governorate.

Methods: The study sample consisted of 1000 healthy Egyptian children of both sexes aged from (5- 12 years) were selected from different urban and rural primary schools. They were examined by tongue depressors in the day light, mouth mirrors and light torch for recording presence or absence of teeth.

Results: The first permanent tooth to erupt was the lower first molar, erupted at 7.30, 7.41 years in girls and boys respectively and the last tooth to erupt was the maxillary second molar, erupted at $11.23,11.26$ years in girls and boys respectively. Also there were no statistically significant gender differences in mean eruption ages of permanent teeth except lower canine and no significant jaw differences except incisors in both girls and boys \&canines and lower second molar in girls. Finally there were insignificant differences between right and left sides in permanent dentition.
\end{abstract}

Conclusion: The eruption dates of permanent teeth are delayed in EL-Gharbia governorate compared to other studies. Girls preceded boys only in lower canine.

KEYWORDS: Tooth Eruption, chronology and sequence of tooth eruption; permanent teeth eruption.

* Pediatric Dentistry Department, Faculty of Dentistry, Tanta University, Tanta, Egypt

** Oral Biology Department, Faculty of Dentistry Department, Tanta University, Tanta, Egypt 


\section{INTRODUCTION}

Eruption of teeth is a normal physiological phenomenon which starts with the eruption of primary teeth, and then followed by permanent teeth. This process is an orderly, sequential and age-specific event. Most parents are anxious about the eruption date which is considered as an important event during a child's development ${ }^{(1)}$.

Teeth eruption includes the entire embryological process from the formation of the tooth germs to calcification, crown formation and root formation. While teeth emergence refers to the appearance of the developing tooth in the oral cavity. Thus the emergence is only one part of the total eruption process. So the tooth eruption is a continuous biological process and tightly regulated process. ${ }^{(2,3)}$

Various theories have been explained the tooth eruption process as eruption is a multi-factorial process, whose biological mechanism remains unknown. Root growth, dentine formation, proliferation of the dental pulp, the periodontal ligament, the connection between the enamel organ and the oral epithelium and the role of the dental follicle; including its innervations and blood supply, are considered to be essential ${ }^{(4)}$.

The time of tooth eruption is influenced by various factors physiological factors (i.e. heredity, geographic factors, sex, race, nutrition, climate and urbanization), pathological systemic factors i.e. endocrine diseases, cerebral palsy, severe renal diseases and genetic disorders) and pathological local factors (local eruption obstacles, hypodontia and lack of space) ${ }^{(5,6)}$.

\section{MATERIALS AND METHODS}

\section{Study design and setting}

Observational Cross-sectional study was conducted on both sexes of children in the primary schools (public and private) in both urban and rural areas in El-Gharbia governorate.

\section{Sample size}

In the present study, a number of 1000 healthy Egyptian children were examined (500 girls and 500 boys) aged from 5 to 12 years were selected randomly from different urban and rural primary schools from the eight centers of El-Gharbia governorate.

The study received ethical approval from the Committee of Research on Humans, Faculty of Dentistry Tanta University. Prior to the study; a written consent was obtained from director of schools. Also written ascent was taken from children older than 7 years old.

The examination of children was performed with the aid of disposable tongue depressors under natural light. A tooth was considered "erupted" if any part of it has penetrated the oral mucosa taking score land tooth considered' 'absent" taking score 0 indicated that the tooth had still been unerupted. ${ }^{(7)}$

\section{RESULTS}

\section{A) Comparison between girls and boys in mean eruption ages of permanent teeth:}

Table (1) showed no statistically significant differences between mean ages of eruption of upper permanent teeth in girls and boys. Also there were no statistically significant differences between mean ages of eruption of lower permanent teeth except lower canine.

\section{B) Comparison between upper and lower jaws in mean eruption ages of permanent teeth in both girls and boys.}

Table (2) showed no significant differences between upper and lower teeth except central, lateral incisors, canine and second molar in girls. While in boys, there were no significant differences between upper and lower teeth except central and lateral incisors. 
TABLE (1): Comparison between girls and boys in mean eruption ages of permanent teeth.

\begin{tabular}{|c|c|c|c|c|c|c|c|c|c|}
\hline \multicolumn{2}{|c|}{ Gender } & \multirow{2}{*}{\multicolumn{3}{|c|}{$\begin{array}{c}\text { girls } \\
\text { Mean } \pm \text { S.D }\end{array}$}} & \multirow{2}{*}{\multicolumn{3}{|c|}{$\begin{array}{c}\text { boys } \\
\text { Mean } \pm \text { S.D }\end{array}$}} & \multirow{3}{*}{$\begin{array}{c}\text { T.test } \\
1.04\end{array}$} & \multirow{3}{*}{$\begin{array}{c}\text { P-value } \\
0.3\end{array}$} \\
\hline Jaw & Tooth & & & & & & & & \\
\hline \multirow{7}{*}{ 产 } & 1 & 7.82 & \pm & 0.77 & 7.91 & \pm & 0.75 & & \\
\hline & 2 & 8.24 & \pm & 0.55 & 8.27 & \pm & 0.54 & 0.29 & 0.76 \\
\hline & 3 & 11 & \pm & 0.69 & 11.2 & \pm & 0.64 & 1.51 & 0.13 \\
\hline & 4 & 10.7 & \pm & 0.81 & 10.8 & \pm & 0.83 & 1.38 & 0.16 \\
\hline & 5 & 10.9 & \pm & 0.74 & 11 & \pm & 0.73 & 0.86 & 0.39 \\
\hline & 6 & 7.42 & \pm & 0.93 & 7.51 & \pm & 0.93 & 1.04 & 0.29 \\
\hline & 7 & 11.2 & \pm & 0.56 & 11.3 & \pm & 0.73 & 0.21 & 0.83 \\
\hline \multirow{7}{*}{ 㐫 } & 1 & 7.41 & \pm & 0.95 & 7.52 & \pm & 0.92 & 1.27 & 0.2 \\
\hline & 2 & 7.85 & \pm & 0.77 & 7.96 & \pm & 0.72 & 1.23 & 0.21 \\
\hline & 3 & 10.7 & \pm & 0.82 & 11 & \pm & 0.76 & 2.72 & $0.00001 *$ \\
\hline & 4 & 10.7 & \pm & 0.81 & 10.8 & \pm & 0.81 & 0.89 & 0.37 \\
\hline & 5 & 10.8 & \pm & 0.79 & 11 & \pm & 0.71 & 1.83 & 0.06 \\
\hline & 6 & 7.3 & \pm & 1.01 & 7.41 & \pm & 0.98 & 1.23 & 0.21 \\
\hline & 7 & 11 & \pm & 0.65 & 11.2 & \pm & 0.74 & 1.14 & 0.25 \\
\hline
\end{tabular}

TABLE (2): Comparison of the mean eruption ages of permanent teeth between upper and lower jaws in both girls and boys

\begin{tabular}{|c|c|c|c|c|c|c|c|c|}
\hline \multirow{2}{*}{ Tooth } & \multicolumn{3}{|c|}{ Upper jaw } & \multicolumn{3}{|c|}{ Lower jaw } & \multirow{2}{*}{ T. test } & \multirow{2}{*}{ P-value } \\
\hline & \multicolumn{3}{|c|}{ Mean \pm SD } & \multicolumn{3}{|c|}{ Mean \pm SD } & & \\
\hline \multicolumn{9}{|c|}{ Grils } \\
\hline 1 & 7.82 & \pm & 0.77 & 7.41 & \pm & 0.95 & 4.57 & $0.0006^{*}$ \\
\hline 2 & 8.24 & \pm & 0.55 & 7.85 & \pm & 0.77 & 4.01 & $0.0008^{*}$ \\
\hline 3 & 11 & \pm & 0.69 & 10.7 & \pm & 0.82 & 3.39 & $0.0008^{*}$ \\
\hline 4 & 10.7 & \pm & 0.82 & 10.7 & \pm & 0.81 & 0.68 & 0.49 \\
\hline 5 & 10.9 & \pm & 0.75 & 10.8 & \pm & 0.79 & 1.06 & 0.29 \\
\hline 6 & 7.43 & \pm & 0.94 & 7.3 & \pm & 1.01 & 1.37 & 0.17 \\
\hline 7 & 11.2 & \pm & 0.57 & 11 & \pm & 0.66 & 1.77 & $0.007 *$ \\
\hline \multicolumn{9}{|c|}{ Boys } \\
\hline 1 & 7.91 & \pm & 0.76 & 7.52 & \pm & 0.92 & 4.17 & $0.00002 *$ \\
\hline 2 & 8.27 & \pm & 0.54 & 7.96 & \pm & 0.72 & 2.64 & $0.008 *$ \\
\hline 3 & 11.2 & \pm & 0.64 & 11 & \pm & 0.76 & 1.91 & 0.057 \\
\hline 4 & 10.8 & \pm & 0.84 & 10.8 & \pm & 0.81 & 0.19 & 0.85 \\
\hline 5 & 11 & \pm & 0.73 & 11 & \pm & 0.71 & 0.24 & 0.8 \\
\hline 6 & 7.51 & \pm & 0.93 & 7.41 & \pm & 0.98 & 1.13 & 0.25 \\
\hline 7 & 11.3 & \pm & 0.73 & 11.2 & \pm & 0.74 & 0.46 & 0.64 \\
\hline
\end{tabular}


C) Comparison between right and left sides in mean eruption ages of permanent teeth

Table (3) showed no significant differences between right and left sides in mean eruption ages of permanent teeth in both girls and boys.

\section{D) Sequence of eruption of primary teeth in girls and boys}

The sequence of eruption of permanent teeth in girls were as follow lower first molar, lower central incisor, upper first molar, upper central incisor lower, upper lateral incisor, upper first premolar, lower canine, lower first premolar, lower, upper second premolar , upper canine lower second molar and upper second molar

While in boys lower, upper first molar, lower, upper central incisor, lower, upper lateral incisor, upper, lower first premolar, lower canine, upper, lower second premolar, lower second molar, upper canine and upper second molar.

TABLE (3): Comparison between right and left sides in mean eruption ages of permanent teeth in both girls and boys.

\begin{tabular}{|c|c|c|c|c|c|c|c|c|c|}
\hline \multirow{2}{*}{3} & \multirow{2}{*}{ Tooth } & \multicolumn{3}{|c|}{ Right side } & \multicolumn{3}{|c|}{ Left side } & \multirow{2}{*}{ T.test } & \multirow{2}{*}{ P-value } \\
\hline & & & \pm & & & & SD & & \\
\hline \multicolumn{10}{|c|}{ Grils } \\
\hline \multirow{7}{*}{ Upper } & 1 & 7.8 & \pm & 0.8 & 7.8 & \pm & 0.8 & 0.12 & 0.9 \\
\hline & 2 & 8.2 & \pm & 0.6 & 8.3 & \pm & 0.6 & 0.11 & 0.9 \\
\hline & 3 & 11 & \pm & 0.7 & 11 & \pm & 0.7 & 0.51 & 0.61 \\
\hline & 4 & 11 & \pm & 0.8 & 11 & \pm & 0.8 & 0 & 1 \\
\hline & 5 & 11 & \pm & 0.7 & 11 & \pm & 0.7 & 0.53 & 0.59 \\
\hline & 6 & 7.4 & \pm & 0.9 & 7.4 & \pm & 1 & 0 & 1 \\
\hline & 7 & 11 & \pm & 0.6 & 11 & \pm & 0.6 & 0.44 & 0.66 \\
\hline \multirow{7}{*}{ Lower } & 1 & 7.4 & \pm & 1 & 7.4 & \pm & 1 & 0 & 1 \\
\hline & 2 & 7.9 & \pm & 0.8 & 7.9 & \pm & 0.8 & 0 & 1 \\
\hline & 3 & 11 & \pm & 0.8 & 11 & \pm & 0.8 & 0.11 & 0.9 \\
\hline & 4 & 11 & \pm & 0.8 & 11 & \pm & 0.8 & 0.11 & 0.91 \\
\hline & 5 & 11 & \pm & 0.8 & 11 & \pm & 0.8 & 0.66 & 0.51 \\
\hline & 6 & 7.3 & \pm & 1 & 7.3 & \pm & 1 & 0.11 & 0.91 \\
\hline & 7 & 11 & \pm & 0.7 & 11 & \pm & 0.6 & 0.33 & 0.73 \\
\hline \multicolumn{10}{|c|}{ Boys } \\
\hline \multirow{7}{*}{ 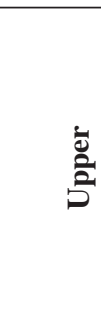 } & 1 & 7.9 & \pm & 0.8 & 8 & \pm & 0.7 & 0.56 & 0.57 \\
\hline & 2 & 8.3 & \pm & 0.5 & 8.3 & \pm & 0.5 & 0.09 & 0.92 \\
\hline & 3 & 11 & \pm & 0.6 & 11 & \pm & 0.7 & 0.24 & 0.81 \\
\hline & 4 & 11 & \pm & 0.8 & 11 & \pm & 0.8 & 0.4 & 0.69 \\
\hline & 5 & 11 & \pm & 0.7 & 11 & \pm & 0.8 & 0.73 & 0.46 \\
\hline & 6 & 7.5 & \pm & 0.9 & 7.5 & \pm & 0.9 & 0.23 & 0.82 \\
\hline & 7 & 11 & \pm & 0.7 & 11 & \pm & 0.8 & 0.21 & 0.83 \\
\hline \multirow{7}{*}{ 㐫 } & 1 & 7.5 & \pm & 0.9 & 7.5 & \pm & 0.9 & 0.23 & 0.81 \\
\hline & 2 & 8 & \pm & 0.7 & 8 & \pm & 0.7 & 0.57 & 0.65 \\
\hline & 3 & 11 & \pm & 0.8 & 11 & \pm & 0.8 & 0.67 & 0.5 \\
\hline & 4 & 11 & \pm & 0.8 & 11 & \pm & 0.8 & 0.56 & 0.57 \\
\hline & 5 & 11 & \pm & 0.7 & 11 & \pm & 0.8 & 1.36 & 0.17 \\
\hline & 6 & 7.4 & \pm & 1 & 7.4 & \pm & 1 & 0.22 & 0.82 \\
\hline & 7 & 11 & \pm & 0.7 & 11 & \pm & 0.6 & 0.14 & 0.88 \\
\hline
\end{tabular}




\section{DISCUSSION}

Eruption date of teeth is determined by specific statistical methods based on data collected from population-wide samples. This process suffers a wide physiological individual variability depending on heredity, geographic factors, sex, race, nutrition, climate and urbanization. ${ }^{(8)}$

The study aimed to determine the eruption dates of permanent teeth, study bilateral and maxillomandibular differences in the eruption of teeth and to assess the sequence of permanent teeth eruption among a group of children in El-Gharbia governorate and we hope that this study can be considered as a starting point for a new national data base for the Egyptians.

The cross-sectional nature of our study enabled us to obtain a sample with less expense and effort. For the study, 1000 children were selected as multistage cluster random sample from the eight centers of El-Gharbia governorate to represent all socioeconomic levels.

In the statistical calculations, the mean age of eruption was used because this method was considered more appropriate to this type of cross sectional study, which does not directly observe the moment when tooth eruption commences. ${ }^{(9)}$

In our study we found that the mandibular first molars were first to erupt at 7.38 years in girls and 7.45 years in boys. These findings were similar to the findings of Grewal et al ${ }^{(10)}$ and Moslemi M ${ }^{(11)}$. On the contrary Helm $S^{\left({ }^{(12)}\right.}$ found that the first molar in each jaw and the mandibular central incisor showed similar eruption time. While Almonaitietine $\mathrm{R}$ et al. ${ }^{(13)}$ found that the earliest permanent tooth to erupt just before the 5 years of age were the lower central incisor for girls and the mandibular first molar for boys. This may be due to different biological, cultural influences, differences in methodologies, age ranges and sample sizes which may affect findings and weaken comparability.
In our study, eruption of permanent teeth was delayed and this disagree with Shaweesh A (14), Khan $\mathrm{N}^{(15)}$, Nichifor $\mathrm{M}$ etal ${ }^{(16)}$ and Chunthuiliu $\mathrm{K}$ and Limbu $\mathrm{D}^{(17)} \quad$ Also the eruption of permanent teeth showed no significant gender differences except for lower canine where girls preceded boys. The same results were nearly observed by El-Hakam $\mathrm{R}$ etal ${ }^{(18)}$, Mahmoud R etal ${ }^{(19)}$, Khatskevich $\mathrm{G}^{(20)}$ and Friedrich $\mathrm{R}^{(21)}$ The differences in permanent teeth eruption between girls and boys in our study ranged from 1-3 months with the largest difference being seen in mandibular canine (3months). These results disagreed with Nichifor M etal ${ }^{(16)}$ Hussin A etal (22) and Dahiya B etal ${ }^{(23)}$ where they have shown that there were significant differences between girls and boys in all the teeth. This earlier eruption was explained to be a sign of earlier physical maturation of girls when compared to boys ${ }^{(24)}$.

The results of eruption of permanent teeth showed no significant jaw differences except incisors in both girls and boys \&canines and lower second molar in girls. It was also observed that the mandibular teeth have an earlier eruption time than the maxillary teeth except premolars. This earlier eruption of mandibular teeth may be the result of the earlier formation of the mandible during its embryonic development than maxilla accordingly the mandibular teeth are expected to form and erupt before the maxillary teeth. This is in agreement with several similar studies carried out in various countries like Hernandez M etal ${ }^{(25)}$ Reddy $\mathrm{K}^{(26)}$ and Shaweesh A etal (27).

The results of eruption of permanent teeth showed no significant contralateral (right and left) teeth differences which corroborates the findings of Elham F and Adhamy S ${ }^{(7)}$ Hughes T etal ${ }^{(28)}$ and Kim C etal ${ }^{(29)}$.However Kaur I. ${ }^{(30)}$ found that most of upper teeth erupted earlier, on right side and in lower jaw teeth erupted earlier on left side.

In our study, the sequence of eruption time of permanent incisors and first molar in girls go with 
Singh $\mathrm{K}^{(31)}$ and Shaweesh $\mathrm{A}^{(\mathbf{1 4})}$ and the sequence of eruption of the permanent canines, premolars and second molar coincided with the findings of Wedl etal. ${ }^{(32)}$ and Shaweesh $\mathrm{A}^{(14)}$.While in boys, the sequence of eruption time of incisors and first molar go with El-Hakam $\mathrm{R}^{(\mathbf{1 8 )}}$ and the sequence of eruption of the canines, premolars and second permanent molar goes with Mahmoud $\mathrm{R}^{(\mathbf{1 9 )}}$.

\section{CONCLUSIONS}

Depending upon the results of this study, we can conclude that:

- The eruption dates of permanent teeth are delayed in EL-Gharbia governorate compared to other studies.

- Girls preceded boys in permanent dentition in lower canines.

- Contralateral teeth erupted within the same period of time in permanent dentition.

\section{RECOMMENDATIONS}

1. X ray examination should also be used for more accuracy.

2. Our researchers and clinicians should rely on Egyptian data, after its construction when taking decisions during diagnosis and treatment plan strategies.

3. Further researches should be done in countries around the world so that the eruption dates and sequence of eruption between the different racial groups in worldwide can be established.

\section{REFERENCES}

1. Pahkala R, Pahkala A, Laine T. Eruption pattern Pahkala R, Pahkala A, Laine T. Eruption pattern of permanent teeth in a rural community in northeastern Finland. Acta Odontol Scand. 1991; 49: 341-349.

2. Ciaparelli L. The chronology of dental development and age assessment. Practical Forensic Odontology. Oxford. $1992 ; 13: 22-42$
3. Sato $\mathrm{S}$ and Parsons P. Eruption of permanent teeth. Ishiyaku Euro America. Inc. Publishers, 1990:95-115.

4. Raghoebar G M , Boering G, Vissink A, Stegenga B. Eruption disturbances of permanent molars. J Oral Pathol Med. 1991; 20(4): 159-166.

5. Denloye O. Eruption sequence of first permanent teeth in some Nigerian children. Ped Dent J .2008; 18: 1-4.

6. Singh K. Age estimation from eruption of temporary and permanent teeth from 6 months to 25 years. J Ind Acad Forensic Med. 2005; 27 (4): 231-235.

7. Elham F and Adhamy S. Age and sequence of permanent canine and premolar teeth eruption in 102-174 months old children in Kerman Province. Current Research in Dentistry. 2010; 1: 6-10.

8. Almonaitiene R, Balciuniene I, Tutkuviene J.Factors influencing permanent teeth eruption. Part one-general factors. Stomatologija J. 2012;12(3).67-72 :

9. Feraru V, Raducanu A, Simona F, Claudiu H. The Sequence and Chronology of the Eruption of Permanent Canines and Premolars in a Group of Romanian Children in Bucharest. OHDM. 2011; 10(4): 193-198.

10. Grewal R S .Medical jurisprudence and toxicology. 1st ed. India: Scientific Book Agency. 1973: 40-41.

11. Moslemi M. An epidemiological survey of the time and sequence of eruption of permanent teeth in 4-15-year-olds in Tehran, Iran. Int J Paediatr Dent. 2004; 14 (6): 432-438

12. Helm S and Seidler B. Timing of permanent tooth emergence in Danish children. Community Dent Oral Epidemiol J. 1974 ; 2 (3): 122-129.

13. Almonaitiene R, Balciuniene I , Tutkuviene J.Factors influencing permanent teeth eruption. Part one-general factors. Stomatologija J. 2012;12(3).67-72 :

14. Shaweesh A .Timing and sequence of emergence of permanent teeth in the Jordanian population. Arch Oral Biol.2012; 57: 122-130.

15. Khan N. Eruption time of permanent teeth in Pakistani children. Iran J Public Health. 2011; 40(4): 63-73.

16. Nichifor M, Scutariu M M , Mocanu C A , Crauciuc E, Ungureanu E .Study regarding the sequence of eruption of permanent teeth at a group of children from Buzu .Genetics and Molecular Biology J .2011 ;12:85-93 
17. Chunthuiliu K and Limbu D K. Eruption of Permanent Teeth among the Gowda Girls of Kodagahalli Village of Mysore District of Karnataka. Anthropologist J. 2013; 16(3):731-734.

18. El-Hakam R, Taha S, El Yazeed M, Rania A. The eruption sequence of primary and permanent teeth in a group of children in Kafr El-Sheikh Governorate, Egypt. International Research J. 2015; 4(8): 1-14.

19. Mahmoud R, Taha S, El Yazeed M. The eruption sequence of primary and permanent teeth in a group of children in Giza Governorate, Egypt. MD Thesis, Faculty of Oral and Dental Medicine, Cairo University, 2015.

20. Khatskevich GA and ogomolova IA. Time of permanent teeth eruption in school children of Saint-Petersburg. Stomatologiia (Mosk) J .2004. 83(3): 53-57.

21. Friedrich R E, Leist A, Scheuer H A. Eruption times of permanent teeth in children and adolescents in the German state of Saarland. Arch Kriminol. 2008; 222: 73-104.

22. Hussin A S, Naing L, Mokhtar N, Taylor JA . The timing and sequence of emergence of permanent teeth in Malay school children in Kota Bharu, Malaysia. Archives of Orofacial Sciences. 2007; 2:36-40.

23. Dahiya B, Singh V, Shahida P, Singh H , Singh D. Age Estimation from Eruption of Permanent Teeth as a Tool for Growth Monitoring. J Indian Acad Forensic Med. 2013; 35 (2):148-150.

24. Seow W K . Effects of preterm birth on oral growth and development. Aust Dent J. 1997; 42(2): 85-91.
25. Hernandez M, Espasa E, Boj J R. Eruption chronology of the permanent dentition in Spanish children. J Clin Pediatr Dent. 2008; 32(4): 347-350.

26. Reddy K S .The Essentials of Forensic Medicine and Toxicology.29th ed. India, 2010: 61-64.

27. Shaweesh A I , Al-Omiri M, Alsoleihat F. Variation in time of emergence of permanent teeth among urban and rural Jordanian school children. Saudi Med J 2011; 32(10):1066-1072.

28. Hughes T E, Bockmann M R ,Seow K. Strong genetic control of emergence of human primary incisors. J Dent Res. 2007; 86:1160-1165.

29. Kim C, Hong Y, Han D H ,Hong HK ,Kim Y N , Bae K $\mathrm{H}$. A prospective cohort study on emergence of permanent teeth and caries experience in Korean children. Int J Paediatr Dent. 2011; 21(4): 254-260.

30. Kaur I, Singal P , Bhatnagar D P . Timing of Permanent Teeth Emergence and Dental Caries among Jatsikh Children of Public and Government Schools of Patiala District. Anthropologist J. 2010;12 (2): 141-148.

31. Singh K. Age estimation from eruption of temporary and permanent teeth from 6 months to 25 years. J Ind Acad Forensic Med. 2005; 27 (4): 231-235.

32. Wedl J S, Schoder V, Blake F A, Schmelzle R ,Friedrich R E. Eruption times of permanent teeth in teenage boys and girls in Izmir (Turkey). J Clin Forensic Med. 2004; 11(6): 299-302. 